Document downloaded from:

http://hdl.handle.net/10251/65716

This paper must be cited as:

Müller, A.; Favennec, J.; Sanabria-Codesal, E. (2015). Coupling matrix filter synthesis based on reflection matrices. Asia-Pacific Microwave Conference (APMC 2015). IEEE. doi:10.1109/APMC.2015.7411795.

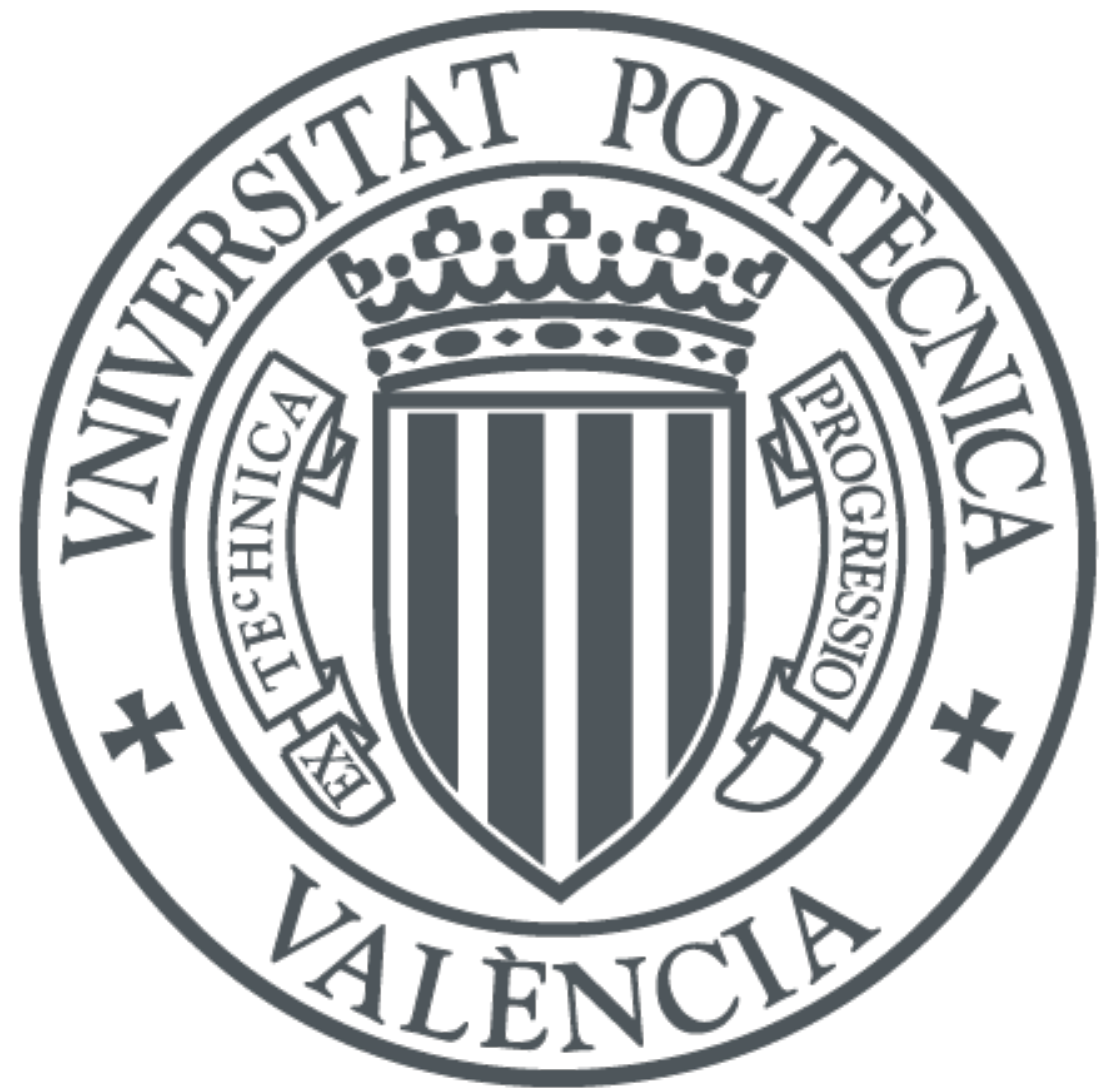

The final publication is available at

http://dx.doi.org/10.1109/APMC.2015.7411795

Copyright IEEE

Additional Information

(C) 2015 IEEE. Personal use of this material is permitted. Permission from IEEE must be obtained for all other uses, in any current or future media, including reprinting/republishing this material for advertising or promotional purposes, creating new collective works, for resale or redistribution to servers or lists, or reuse of any copyrighted component of this work in other works. 


\title{
Coupling matrix filter synthesis based on reflection matrices
}

\author{
A. A. Muller ${ }^{1}$, J-F. Favennec ${ }^{2}$, E. Sanabria-Codesal ${ }^{3}$ \\ ${ }^{1}$ Microwave Applications Group- I-Team, Universitat Politècnica de València, Valencia, 46022 Spain \\ ${ }^{2}$ Université de Brest, Lab-STICC UMR CNRS 6285, 6 Av Le Gorgeu, CS 93837, 29238 Brest Cedex 3 France \\ ${ }^{3}$ Departamento de Matemática Aplicada, Universitat Politècnica de València, Valencia, 46022 Spain
}

\begin{abstract}
The paper introduces the concept of reflection matrices in the coupling matrix filter reconfiguration. It is shown that reflection matrices are complementary to rotation matrices a useful concept that can be used alternatively to rotation matrices in the similarity transformations that are applied in order to transform the coupling matrix to a suitable form. A cross-coupled filter example is given where both concepts are used.
\end{abstract}

\section{INTRODUCTION}

The starting point of the coupling matrix synthesis in the design of microwave filters can be related with the seminal work [1]. The $N^{*} N$ coupling matrix that characterizes the $N$ coupled resonators can be reconfigured into more suitable coupling matrices using similarity transformations based on Givens rotations [1-4] or by means of optimization techniques [5] mainly described in [6]. The $N+2$ coupling matrix usage on the other hand is related to the decisive work in [7] in which the authors allow the presence of the source-load crosscoupling in order to introduce more transmission zeros. The $N+2$ transversal coupling matrix synthesis directly from the scattering matrix [4] represents a key point in the filter synthesis theory. However since the transversal coupling matrix is not practical, the authors reconfigure it using similarity transformations employing rotations $[2,3,5,6]$ or again by means of different optimization techniques [8].

In this work we focus on the similarity transformations used to reconfigure (both $N$ or $N+2$ ) coupling matrices and show that besides the well known rotation matrices $[1-4,6,9,10]$, the reflection matrices (unused to the best of our knowledge up to now in microwave filter theory) may be employed alternatively too in order to deliver a convenient topology.

In [1] in order to reconfigure a symmetrical matrix into a different symmetrical matrix sharing the same Eigenvalues, the authors use from [11] the concept of (orthogonal) Givens rotation matrices and apply these ones as similarity transformations [11] to their initial synthesized coupling matrix

Reflection matrices on the other hand are found in the group theory in geometry [12] (introduced by Felix Klein), mainly in Euclidean transformations and also belong to the class of orthogonal transformations forming together with the rotation matrices a group. They are used complementary to rotation matrices for connecting the Riemann sphere with the Möbius transformations (named conjugate transformations [12]) and (when used in microwave theory) can relate the impedance plane to the reflection coefficient's plane on the 3D Smith chart [13-14]. As rotation matrices, when applied as similarity transformations [12], they map a symmetrical matrix into a new symmetrical matrix with the same Eigenvalues.

In this paper we begin by introducing the concept of reflection matrix and then starting from the transversal coupling matrix of a desired filter [4] we reconvert it to a folded one [2] using both rotation matrices and reflection matrices (or by mixing them) and compare the results. Finally we present a HFSS filter design based on an obtained folded coupling matrix.

\section{REFLECTION MATRICES}

Similar matrices are matrices which share the same Eigenvalues and can be obtained from an initial matrix applying transformation (1) where $T$ has to be an invertible matrix. In the case of a lossles filter the coupling matrix $M$ is real and symmetric, thus in order to obtain a new symmetric matrix which should be similar to the first one has to apply orthogonal transformations [1-4]. Reflection matrices are orthogonal matrices with determinant -1 while rotation matrices orthogonal matrices with determinant 1 [12].

$$
\left[M^{\prime}\right]=[T][M][T]^{t}
$$

The main building block of the rotation matrices has the form (2) while the main block of the reflection matrices has form (3).

$$
\begin{aligned}
& T_{R}=\left(\begin{array}{cc}
\operatorname{Cos}(\theta) & -\operatorname{Sin}(\theta) \\
\operatorname{Sin}(\theta) & \operatorname{Cos}(\theta)
\end{array}\right) \\
& T_{r}=\left(\begin{array}{cc}
\operatorname{Cos}(\theta) & \operatorname{Sin}(\theta) \\
\operatorname{Sin}(\theta) & -\operatorname{Cos}(\theta)
\end{array}\right)
\end{aligned}
$$


III. FILTER SYNTHESIS BASED ON THE TRANSVERSAL COUPLING MATRIX AND IT'S RECONFIGURATION BY MEANS OF ROTATION AND REFLECTION MATRICES

Let us consider the example of a 4 order Chebyshev filter with a central frequency of $1850 \mathrm{MHz}$, bandwidth of $20 \mathrm{MHz}$ and the return loss of $22 \mathrm{~dB}$. The filter whose layout (but no information about the design strategy) may be found [15] is designed by means of the next procedure. Following the method proposed in [4], the transversal coupling matrix $M_{l}$ of the filter is first generated in the baseband considering two transmission zeros at $\omega=1.7$ and $\omega=-1.7$ ( $\omega$ is the angular frequency $\mathrm{rad} / \mathrm{s}$ ) getting $M_{1}$ as (4), while the frequency response as in Fig.1.

$M_{1}=\left(\begin{array}{cccccc}0 & 0.659244 & 0.659244 & 0.360707 & 0.360707 & 0 \\ 0.659244 & -0.775083 & 0 & 0 & 0 & -0.659244 \\ 0.659244 & 0 & 0.775083 & 0 & 0 & 0.659244 \\ 0.360707 & 0 & 0 & -1.31444 & 0 & 0.360707 \\ 0.360707 & 0 & 0 & 0 & 1.31444 & -0.360707 \\ 0 & -0.659244 & 0.659244 & 0.360707 & -0.360707 & 0\end{array}\right)$

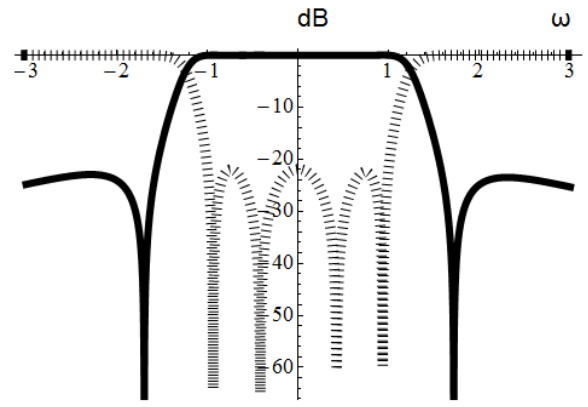

Figure 1. Return loss (dotted) and transmission coefficient for the filter topology generated by (4).

The first row (column) of the transversal coupling matrix (4) contains the values for the couplings between the source and the four resonators $M_{S k}$, while the last row (column) is filled by the values of the couplings between the resonators and the load $M_{k L}$ (where $\left.1 \leq k \leq 4\right)$ in our case (since it is a forth order filter) There are no direct source-load cross-couplings $\left(M_{S L}=M_{L S}=0\right)$. Using the rotation matrices and applying them 6 successive times [2] in (1) to the matrix $M_{l}$ we get a folded matrix of form (5). The rotation matrices are chosen as in [2] $T_{R I}$ with pivot [3, 4], $T_{R 2}$ with pivot $[2,3]$ and $T_{R 3}$ with pivot $[1,2]$.

$$
M_{2}=\left(\begin{array}{cccccc}
0 & m_{s 1} & 0 & 0 & 0 & 0 \\
m_{s 1} & 0 & m_{12} & 0 & m_{14} & 0 \\
0 & m_{12} & 0 & m_{23} & 0 & 0 \\
0 & 0 & m_{23} & 0 & m_{34} & 0 \\
0 & m_{14} & 0 & m_{34} & 0 & m_{4 L} \\
0 & 0 & 0 & 0 & m_{4 L} & 0
\end{array}\right)
$$

One may see the form of a rotation matrix $T_{R I}$ with pivot $[3,4]$ in (6). The corresponding reflection matrix $T_{r I}$ with pivot $[3,4]$ may be also seen in (6). By applying like in [4] the series of rotations (Table 1) to the initial transversal coupling matrix $M_{l}$ we get $M_{R}(7)$.
$T_{R 1}=\left(\begin{array}{cccccc}1 & 0 & 0 & 0 & 0 & 0 \\ 0 & 1 & 0 & 0 & 0 & 0 \\ 0 & 0 & 1 & 0 & 0 & 0 \\ 0 & 0 & 0 & \operatorname{Cos}[x] & -\operatorname{Sin}[x] & 0 \\ 0 & 0 & 0 & \operatorname{Sin}[x] & \operatorname{Cos}[x] & 0 \\ 0 & 0 & 0 & 0 & 0 & 1\end{array}\right) \quad T_{r 1}=\left(\begin{array}{cccccc}1 & 0 & 0 & 0 & 0 & 0 \\ 0 & 1 & 0 & 0 & 0 & 0 \\ 0 & 0 & 1 & 0 & 0 & 0 \\ 0 & 0 & 0 & \operatorname{Cos}[x] & \operatorname{Sin}[x] & 0 \\ 0 & 0 & 0 & \operatorname{Sin}[x] & -\operatorname{Cos}[x] & 0 \\ 0 & 0 & 0 & 0 & 0 & 1\end{array}\right)$

TABLE I

ROTATION MATRICES AND PIVOTS SEQUENCE FOR THE REDUCTION OF THE TRANSVERSAL COUPLING MATRIX TO A FOLDED ONE

\begin{tabular}{|l|l|l|l|l|}
\hline $\begin{array}{l}\text { Transformation } \\
\text { number }\end{array}$ & $\begin{array}{l}\text { Matrix } \\
\text { name }\end{array}$ & Pivot & $\begin{array}{l}\text { Pivot value } \\
(\mathrm{x})\end{array}$ & $\begin{array}{l}\text { Coupling } \\
\text { Element } \\
\text { annihilated }\end{array}$ \\
\hline 1 & $\mathrm{~T}_{\mathrm{R} 1}$ & {$[3,4]$} & -0.78539 & $\mathrm{M}_{\mathrm{S} 4}$ \\
\hline 2 & $\mathrm{~T}_{\mathrm{R} 2}$ & {$[2,3]$} & -0.65855 & $\mathrm{M}_{\mathrm{S} 3}$ \\
\hline 3 & $\mathrm{~T}_{\mathrm{R} 3}$ & {$[1,2]$} & -0.90164 & $\mathrm{M}_{\mathrm{S} 2}$ \\
\hline 4 & $\mathrm{~T}_{\mathrm{R} 2}$ & {$[2,3]$} & -1.12328 & $\mathrm{M}_{2 \mathrm{~L}}$ \\
\hline 5 & $\mathrm{~T}_{\mathrm{R} 1}$ & {$[3,4]$} & 1.07014 & $\mathrm{M}_{23}$ \\
\hline 6 & $\mathrm{~T}_{\mathrm{R} 2}$ & {$[2,3]$} & 1.57081 & $\mathrm{M}_{13}$ \\
\hline
\end{tabular}

Using just reflection matrices with the same corresponding pivots namely $T_{r 1}$ with pivot [3, 4], $T_{r 2}$ with pivot $[2,3]$ and $T_{r 3}$ with pivot $[1,2]$ and applying them as in Table 2 we get $M_{r}(8)$.

TABLE 2

REFLECTION MATRICES SEQUENCE AND PIVOTS FOR THE REDUCTION OF THE TRANSVERSAL COUPLING MATRIX TO A FOLDED ONE

\begin{tabular}{|l|l|l|l|l|}
\hline $\begin{array}{l}\text { Transformation } \\
\text { number }\end{array}$ & $\begin{array}{l}\text { Matrix } \\
\text { name }\end{array}$ & Pivot & $\begin{array}{l}\text { Pivot } \\
\text { value (x) }\end{array}$ & $\begin{array}{l}\text { Coupling } \\
\text { Element } \\
\text { annihilated }\end{array}$ \\
\hline 1 & $\mathrm{~T}_{\mathrm{r} 1}$ & {$[3,4]$} & 0.78539 & $\mathrm{M}_{\mathrm{S} 4}$ \\
\hline 2 & $\mathrm{~T}_{\mathrm{r} 2}$ & {$[2,3]$} & 0.65855 & $\mathrm{M}_{\mathrm{S} 3}$ \\
\hline 3 & $\mathrm{~T}_{\mathrm{r} 3}$ & {$[1,2]$} & 0.90164 & $\mathrm{M}_{\mathrm{S} 2}$ \\
\hline 4 & $\mathrm{~T}_{\mathrm{r} 2}$ & {$[2,3]$} & 1.12328 & $\mathrm{M}_{2 \mathrm{~L}}$ \\
\hline 5 & $\mathrm{~T}_{\mathrm{r} 1}$ & {$[3,4]$} & 1.07014 & $\mathrm{M}_{23}$ \\
\hline 6 & $\mathrm{~T}_{\mathrm{r} 2}$ & {$[2,3]$} & 1.57081 & $\mathrm{M}_{13}$ \\
\hline
\end{tabular}

TABLE 3

REFLECTION AND ROTATION MATRICES SEQUENCE AND PIVOTS FOR THE REDUCTION OF THE TRANSVERSAL COUPLING MATRIX TO A FOLDED ONE

\begin{tabular}{|l|l|l|l|l|}
\hline $\begin{array}{l}\text { Transformation } \\
\text { number }\end{array}$ & $\begin{array}{l}\text { Matrix } \\
\text { name }\end{array}$ & Pivot & $\begin{array}{l}\text { Pivot } \\
\text { value }(\mathrm{x})\end{array}$ & $\begin{array}{l}\text { Element } \\
\text { annihilated }\end{array}$ \\
\hline 1 & $\mathrm{~T}_{\mathrm{r} 1}$ & {$[3,4]$} & 0.78539 & $\mathrm{M}_{\mathrm{S} 4}$ \\
\hline 2 & $\mathrm{~T}_{\mathrm{r} 2}$ & {$[2,3]$} & 0.65855 & $\mathrm{M}_{\mathrm{S} 3}$ \\
\hline 3 & $\mathrm{~T}_{\mathrm{r} 3}$ & {$[1,2]$} & 0.90164 & $\mathrm{M}_{\mathrm{S} 2}$ \\
\hline 4 & $\mathrm{~T}_{\mathrm{r} 2}$ & {$[2,3]$} & 1.12328 & $\mathrm{M}_{2 \mathrm{~L}}$ \\
\hline 5 & $\mathrm{~T}_{\mathrm{R} 1}$ & {$[3,4]$} & -1.07014 & $\mathrm{M}_{23}$ \\
\hline 6 & $\mathrm{~T}_{\mathrm{R} 2}$ & {$[2,3]$} & 1.57081 & $\mathrm{M}_{13}$ \\
\hline
\end{tabular}

Considering now the succession of reflection and rotation matrices applied to (4) presented in Table 3 we get $M_{R r}$ (9). It is important to point out that the matrices presented in (4), (7), (8) and (9) share the same Eigenvalues and generate the same 
frequency response as in Fig.1 (keeping the phase of the scattering parameters unchanged too). For example, form (9) is of interest because the filter is now symmetrical and it changes the cross-coupling sign to a positive one.

$M_{R}=\left(\begin{array}{cccccc}0 & 1.06274 & 0 & 0 & 0 & 0 \\ 1.06274 & 0 & 0.879874 & 0 & -0.293658 & 0 \\ 0 & 0.879874 & 0 & 0.833012 & 0 & 0 \\ 0 & 0 & 0.833012 & 0 & 0.879874 & 0 \\ 0 & -0.293658 & 0 & 0.879874 & 0 & -1.06274 \\ 0 & 0 & 0 & 0 & -1.06274 & 0\end{array}\right)$

$M_{r}=\left(\begin{array}{cccccc}0 & 1.06274 & 0 & 0 & 0 & 0 \\ 1.06274 & 0 & -0.879874 & 0 & -0.293658 & 0 \\ 0 & -0.879874 & 0 & 0.833012 & 0 & 0 \\ 0 & 0 & 0.833012 & 0 & -0.879874 & 0 \\ 0 & -0.293658 & 0 & -0.879874 & 0 & -1.06274 \\ 0 & 0 & 0 & 0 & -1.06274 & 0\end{array}\right)$

$M_{R r}=\left(\begin{array}{cccccc}0 & 1.06274 & 0 & 0 & 0 & 0 \\ 1.06274 & 0 & 0.879874 & 0 & 0.293658 & 0 \\ 0 & 0.879874 & 0 & -0.833012 & 0 & 0 \\ 0 & 0 & -0.833012 & 0 & 0.879874 & 0 \\ 0 & 0.293658 & 0 & 0.879874 & 0 & 1.06274 \\ 0 & 0 & 0 & 0 & 1.06274 & 0\end{array}\right)$

\section{A CROSS COUPLED COMBLINE FILTER EXAMPLE}

Although the matrix obtained in (9) if of a practical interest we may further manipulate it and obtain the matrix $M_{F}$ (10) which is similar (has the same Eigenvalues) to (4), (7)-(9) and generates the same frequency response as in Fig.1. It has to be pointed out that (10) may be also obtained using a reflection matrix $T_{r}$ directly from (4) as in (11)-(12). It is easy to check that (11) is a reflection matrix (it has determinant -1 and it is orthogonal).

$$
M_{F}=\left(\begin{array}{cccccc}
0 & 1.06274 & 0 & 0 & 0 & 0 \\
1.06274 & 0 & 0.879874 & 0 & -0.293658 & 0 \\
0 & 0.879874 & 0 & 0.833012 & 0 & 0 \\
0 & 0 & 0.833012 & 0 & 0.879874 & 0 \\
0 & -0.293664 & 0 & 0.879874 & 0 & 1.06274 \\
0 & 0 & 0 & 0 & 1.06274 & 0
\end{array}\right)
$$

$$
T_{r}=\left(\begin{array}{cccccc}
0.157328 & 0 & -0.0896723 & -0.507061 & 0 & -0.842672 \\
-0.227729 & 0.620326 & -0.490535 & 0.394533 & 0.339404 & -0.227725 \\
0.28411 & -0.339413 & -0.501341 & -0.295338 & 0.620322 & 0.284102 \\
-0.284109 & -0.339404 & 0.501334 & 0.295341 & 0.620326 & -0.284113 \\
0.227731 & 0.620322 & 0.490526 & -0.394544 & 0.339413 & 0.227722 \\
0.842668 & 0 & 0.089668 & 0.508067 & 0 & -0.157332
\end{array}\right)
$$

$$
\left[M_{F}\right]=\left[T_{r}\right]\left[M_{1}\right]\left[T_{r}\right]^{t}
$$

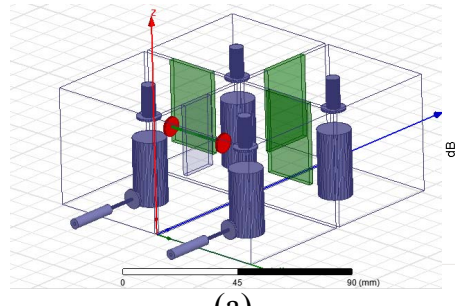

(a)

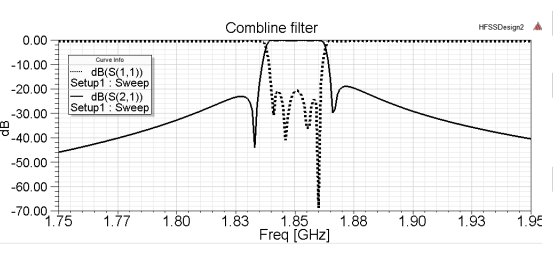

(b)
Figure 2. Combline filter (a) 3D representation and (b) frequency response- of the combline filter starting from (10).
The filter in Fig. 2 is designed and simulated in HFSS starting from (10), the results showing a good insertion and return loss.

\section{CONCLUSION}

The reflection matrices were introduced for the first time (to the best of our knowledge) in the coupling matrix filter synthesis. It was shown that although they annihilate the same elements when applied instead of the rotation matrices in the similarity transformations used to reduce the coupling matrix, they may generate different filter topologies. Combining rotation matrices and reflection matrices in the succession of series of transformations may also prove effective (9). It is not claimed that new filter topologies may be achieved, just that when applied instead of the rotation matrices / or combined with them one may obtain using the same number of transformations different results by using reflection matrices.

\section{ACKNOWLEDGMENT}

This work has been founded by SIWTUNE Marie Curie CIG no 322162 and DGCYT MTM2012-33073 grants. A.A.M. thanks to Dr. R.J Cameron, Prof P. Soto and Prof. V.E. Boria for the fruitful discussions held in Valencia during 2014-2015.

\section{REFERENCES}

[1] A. E. Atia, A. E. Williams, "Narrow-Band Multiple-Coupled Cavity Synthesis" IEEE Trans. Circuits Syst. vol 5, pp. 649-655, 1974.

[2] R. Cameron, "Advanced Filter Synthesis", IEEE Microw. Mag,, vol 12 no. 6, pp 42-61, 2011.

[3] R. Cameron, N. Chandra, R. Mansour, Microwave filters for Communication Systems, Fundamentals, Design, Wiley Interscience, 2007.

[4] R. C. Cameron, "Advanced Coupling Matrix Synthesis Techniques for Microwave filters", IEEE Trans. Microw Theory Techn, vol 51, no 1, pp. 1-10, January 2003.

[5] A. Lamecki, P. Kozakowski, M. Mrosovski, "Fast Synthesis of CrossCoupled resonators" IEEE MWCL, vol 4 no 14, pp 174-176, 2004.

[6] A. Jedrezejewski, L. Sydlowski, A. Lamecki, "Comparison of Optimization Techniques for Coupling Matrix Synthesis Using Eigenvalue Based Approach", [Digests Int. Conference on Microwaves, Radar and Wireless Communicatios], Poland, pp 471-476, 2012.

[7] J. Montejo-Garai, "Synthesis of N-order symmetric filters with Ntransmission zeros by means of source-load cross-coupling, Electronics Letters, vol 4 no 3, pp 232-233, 2000.

[8] P. Kozakowski, A. Lamecki, P.Sypek, M. Mrozoski, "Eigenvalue Approach to Synthesis of Prototype Filters with source/load coupling" IEEE MWCL, vol 15 no 2, pp 98-100, 2005.

[9] G. Macchiarella, S. Tamiazzo, "Generation of Canonical Forms for Multiport Filtering Networks", IEEE MTT-S, pp 1-3, USA, Tampa, 2014

[10] S. Amari, F. Seyfert, M. Bekheit, " Theory of Coupled Resonator Microwave Bandpass Filters of Arbitrary Bandwidth", IEEE Trans. Microw Theory Techn, vol 58 no 8, pp 2188-2203, 2010.

[11] F. R. Gantmacher, The Theory of Matrices, vol 1, New York, Chelsea Publishing, 1952.

[12] D. A. Brannan, M. Esplen, J. J. Gray, Geometry. Cambridge Univ Press UK, 2007.

[13] A. A. Muller, P. Soto, D. Dascalu, D. Neculoiu, V. E. Boria, "A 3D Smith chart based on the Riemann Sphere for Active and Passive Microwave Circuits", IEEE MWCL vol 21, no 6, pp 286-288, 2011.

[14] A. A. Muller, E. Sanabria-Codesal, A. Moldoveanu, V. Asavei, P. Soto, V.E. Boria, S. Lucyszin "Apollonius Unilateral Transducer Power Gain circles on 3D Smith charts", Electronics Letters, vol 50 no 21, pp 15311533, 2014.

[15] A. S. Blas, A. Vidal, A. A. Muller, P. Soto, F. Mira, F. Perez-Soler, B. Gimeno, V. E. Boria, "Flexible and efficient computer aided design tool for advanced combline configuration", INT. J. RF. Microwave C.E. in press ( online), 2015. 